\title{
Development and Innovative Design Research of Underwater Bionic Fish Products under Hybrid Propulsion Technology
}

\author{
Ximing Xia $\mathbb{D}^{1},{ }^{1}$ Naifa Hu, ${ }^{2}$ Jinhui Liu, ${ }^{1}$ Guijiang Chen, ${ }^{3}$ Qinghan Yang, ${ }^{1}$ and Yuyi Chen ${ }^{1}$ \\ ${ }^{1}$ Nanjing Institute of Technology, Jiangsu, China \\ ${ }^{2} 248$ Geological Team of Shandong Nuclear Industry, Shandong, China \\ ${ }^{3}$ Nanjing Yuling Technology Co., Ltd., Jiangsu, China
}

Correspondence should be addressed to Ximing Xia; xiam68@njit.edu.cn

Received 25 October 2021; Revised 14 November 2021; Accepted 15 November 2021; Published 29 November 2021

Academic Editor: Xin Ning

Copyright (c) 2021 Ximing Xia et al. This is an open access article distributed under the Creative Commons Attribution License, which permits unrestricted use, distribution, and reproduction in any medium, provided the original work is properly cited.

For a long time, underwater robot has been used as a scientific research tool and a teaching platform, but the real application products have not been well explored. The successful case of UAV gives underwater robot a higher expectation. How to apply underwater robot and enter the market has become a hot spot of underwater robot research at present. This paper mainly introduces a bionic fish-shaped robot, redefines underwater robot with innovative thinking, determines product functions from the perspective of the market, and develops product functions and designs and realizes the structure of each part according to the existing scientific research experience. Main innovation points of this design are to adopt the way of the hybrid propulsion for underwater robot movement, through the form of a hybrid propulsion and long range and the contradiction between the rapid maneuver, at the same time of umbilical cord cable, using float design improvement, and through the highly integrated ground station for the system operation control.

\section{Introduction}

After 66 years of development, the technology of underwater robot has gradually matured, which is mainly reflected in the miniaturization of its main body, diversification of accessories, and modularization of functions. This paper mainly introduces a hybrid propulsion bionic fish system based on underwater robot technology. The system consists of three parts: the robot body, the fin communication system, and the ground station control system. According to the design requirements of the subject, the mechanical structure design of the system and the stress analysis of key bearing parts are carried out by using Unigraphics NX 10.0. The fluid mechanic analysis of the bionic fish is carried out by combining with Solidworks 2018. The overall design, production, and debugging of the system are carried out according to the basic parameters of the design task book. In order to further develop its functions and enter the application market, the feasibility of underwater bionic robot in the market is explored.
As a tool for exploring underwater space, the main difference between underwater robot and land and air robot lies in the huge difference of working environment medium. As an important technical means and equipment for ocean research and development, underwater robots have been increasingly widely applied in various fields of ocean research and development $[1,2]$. When the robot enters the water, the two problems that must be considered are the influence of water on the normal operation of electronic devices in the robot work and the absorption and shielding of electromagnetic waves by water. Of course, after so many years of development, low-cost solutions for civil use gradually take shape. With the structural upgrading and technological improvement of waterproof sealing chamber, a 300-meter pressure-resistant chamber only needs more than 1,000 yuan. Subsea powertrain solutions are also being miniaturized and productized. At present, a high-power and high-thrust thruster only costs 2,000 yuan. All the signs indicate that the potential for the application market of underwater robots is gradually improving. 
This paper mainly studies a hybrid propulsion bionic fish. The original plan is to use uncabled underwater robot (AUV), but the team still has not solved the problem of low-cost underwater communication; so, the current research stage is still stuck in the level of cabled underwater robot (ROV). During the discussion and development of the scheme, draw lessons from the "Haizheng ii" ARV designed by China Ship Science Research Center. It has three modes of autonomy, remote control, and monitoring for timely selection in complex environment. It has its own energy and is connected with the mother ship through optical fiber. It can conduct search, fixed-point observation and light underwater operations in a medium range [2]. We are looking forward to a new way of thinking to solve the limitations of umbilical cord on the robot's movement space and range, so as to improve its maneuverability and facilitate the market promotion and application of underwater robots.

\section{Research Status: The Development History of Bionic Robots}

People are very famous for the exploration of the bionic robot can be traced back to the earliest of The Three Kingdoms period MuNiu LiuMa, humans have been found in the long process of evolution, biological many details remain very worth learning, and this greatly inspired the exploration of human desire; since September 1960, the first world conference on bionics was held in the United States air force base, Ohio. In the decades since, a host of bionic technologies and devices has emerged. For example, Boston Dynamics, the most familiar company, has been conducting research and development of bionic robots since its establishment in 1992 $[3,4]$. All the robots released have generated a great sensation, from Big Dog to Handle, which has provided great impetus for the development of bionic robots.

2.1. Technical Difficulties and Market Analysis of Bionic Underwater Robot. Biomimetic fish remained in the theoretical stage before the design and production of robofish "RoboTuna" in 1994. Since then, a large number of biomimetic fish have gradually entered the public view, and their shapes are gradually diversifying. With the slow progress of technology, many low-cost waterproof and sealing schemes and reliable communication schemes have been developed, and the bionic fish has also begun to be commercialized. The "KenFish-A-Series" series of Lewisdom Robot is very representative (See Figure 1), providing users with a set of kits that can be built quickly through modular products [5, 6]. This robot uses a steering gear to carry out single-joint movement to provide power to the robot. From the perspective of dynamic structure, the efficiency of this mode of movement is low. In practical use, the movement speed of single-joint bionic fish is less than $0.5 \mathrm{~m} / \mathrm{s}$. The waterproof and sealed shell made of engineering plastic cannot withstand enough water pressure, and communication signal transmission through Wi-Fi cannot solve the problem of underwater communication; so, the robot is summarized.

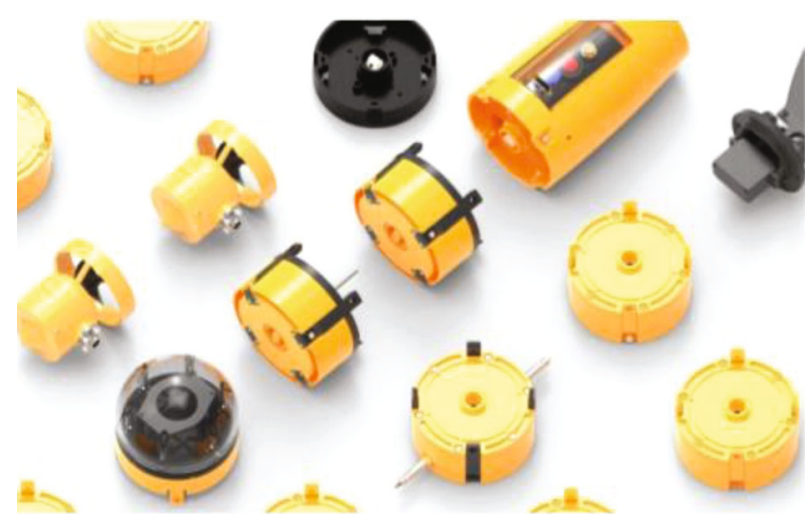

Figure 1: "KenFish-A" series of bionic fish.

2.2. Technical Difficulties and Market Analysis of Bionic Underwater Robot. Compared with "Kenfish-A" series products, another product is relatively effective in solving the problem of underwater communication. The underwater bionic UAV PowerRay is connected to the ground control unit through a long umbilical cable. The control signal is sent by the ground operator and transmitted to the underwater robot by the umbilical cable. Transmission distance is only affected by cable length and signal strength. The maximum transmission distance of this product is 70 meters [7]. But also because of umbilical cord cable connected to the ground, so the robot will be limited to the corresponding activity space, and the main application field for underwater photographs to explore PowerRay, price between 9000 and 14000 , can be seen from the price on the product application field that is actively to market promotion and relatively mature case for the application of sea cucumber breeding base. This is because it is important for sea cucumber farmers to be able to monitor and understand the health status of aquatic products in real time. However, refined aquaculture management not only needs to control the basic water temperature, light, $\mathrm{pH}$ value, and other simple data but also the more important water dissolved oxygen (DO), turbidity, conductivity, and other parameters, which are the main factors directly affecting the production efficiency of aquaculture; so, it can be seen that there is no very appropriate solution in the market $[8,9]$.

To sum up, in the actual research and design, combined with the examples of "KenFish-A" and "PowerRay," it can be seen that the main problems of the current bionic underwater robot are the low-cost waterproof structure and reliable underwater communication scheme. Of course, from these two underwater bionic robots, we can also see that there are two huge markets for the application of underwater robots at present: education industry and fishing and animal husbandry industry. A highly integrated, low-cost underwater bionic fish needs to be designed urgently (see Figure 2).

\section{Hybrid Propulsion Underwater Bionic Fish Structure Design and Implementation}

As the cost of the structure of underwater robot is limited by size, it directly affects the energy system. Hybrid propulsion 


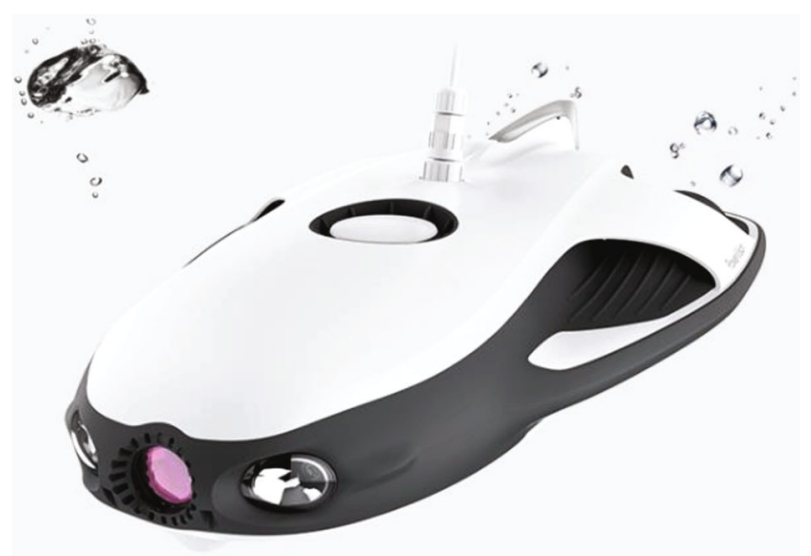

Figure 2: Bionic fish underwater "PowerRay."

is mainly to solve the problem of energy endurance. Based on this, the structure design of bionic fish is carried out by using known parameters. Main design requirements are shown in Figures 3 and 4.

\subsection{Mechanical Structure Design and Production of Bionic Fish}

3.1.1. Mechanical Structure Design of Prototype Machine. Mechanical part design requirements are as follows:

(1) volume length $80 \mathrm{~cm}$, width $35 \mathrm{~cm}$, height $20 \mathrm{~cm}$

(2) The weight is about $35 \mathrm{~kg}$

(3) The maximum diving depth is $100 \mathrm{~m}$

(4) Camera rotation Angle is $\pm 40^{\circ}$

(5) Movement posture adjustment for forward, backward, left turn, right turn, up, diving, a total of 6

Divide each section proportionally according to the target size. From the bionic fish, renderings can be seen: the robot needs to be divided into three parts: camera cabin, chip cabin, and tail. The size of tail is $200 \mathrm{~mm}$ as shown in Figure 5. The total length of camera cabin, chip cabin, and a propeller placed vertically is $600 \mathrm{~mm}$. In order to ensure that the chip cabin can accommodate the chip, battery, and center of gravity adjustment mechanism, it is necessary to reduce the size of the camera cabin as much as possible. The minimum size of the camera cabin is $120 \mathrm{~mm}$; so, the length of the chip cabin is $400 \mathrm{~mm}$.

The overall maximum height is $200 \mathrm{~mm}$ and the maximum width is $350 \mathrm{~mm}$. According to these two parameters, the diameter of the chip cabin barrel is $160 \mathrm{~mm}$. According to the minimum principle of camera cabin, select $90 \mathrm{~mm}$ camera cabin. [9]

According to the above dimensional analysis, the overall structure diagram can be obtained, and the preliminary layout is shown in Figure 5:

The prototype's frame is made of aluminum profile, which has the advantages of easy processing, standardization, ease of procurement, and low cost. It uses a standard connection mode with good internal and external angles, which greatly improves connection strength accuracy. At the same time, the prototype's surface has corrosion resistance characteristics after high temperature oxidation and sand blasting treatments. It is the ideal material for bionic fish frame. The disadvantage of this flexibility is that the solution is not optimal in terms of cost and energy consumption, but a good compromise can be found [10]. The preliminary design of the bionic fish frame is shown in Figure 6.

3.1.2. Selection and Check of Prototype Frame. Considering the streamlined body shape of the bionic fish in the water, the overall size should not be too large, and the profile that occupies the main weight of the bionic fish should be as small and light as possible; so, the minimum size of 1515 alloy profile is selected to build. The concrete material composition is shown in Table 1, and the mechanical properties are shown in Table 2. According to the advanced simulation analysis of Unigraphics NX10.0, the force analysis figure is shown in Figure 7. The verification results show that the profile construction frame meets the use requirements.

\subsection{Design and Check of Each Circuit Cabin of the Bionic} Fish. In the previous innovative experiment, we aggressively poxed all the chip circuits in order to save the unnecessary volume occupied by the tank, but we did not take into account the loss of buoyancy caused by the removal of the tank and the risk caused by the glue-the poxed chip is not removable. Therefore, after comprehensive comparison, although the sealant filling method is more stable and reliable, the tank drum structure is the most convenient and sustainable, which is convenient for later maintenance and debugging.

3.2.1. Structural Design of Tank Drum Seal. Tank barrel structure is mainly divided into three parts: front transparent ball cover, middle main tank, and rear flange end cover. There is no direct mechanical connection between the three parts. The O-ring is used to seal the sealing chamber and the hatch cover, and the power line and control cable pass through the hatch cover through the underwater threading bolt. Among them, after the control cable out of the sealed cabin, through the wire clip out of the upper cover, the cable card is fixed on the mounting hole of the upper cover, and there are compression bolts inside the cable card to fix the cable. The control cable is connected to the remote controller on the ground, which can transmit video signals and control signals. The maximum diving depth of the ROV can reach 100 meters. As we known, the acrylic (PMMA) is used as the main cabin and cabin cover. Its chemical name is polymethyl methacrylate, which is a kind of polymer material with good transparency, chemical stability and weather resistance, easy dyeing, easy processing, and beautiful appearance. It is widely used in the construction industry. Also, because of these advantages, it fully meets our requirements for the tank barrel, and high transparency can very quickly and obviously observe the real-time situation in the cabin, avoid water seepage in the cabin, and let the machine continue to run. The high mechanical strength means the 


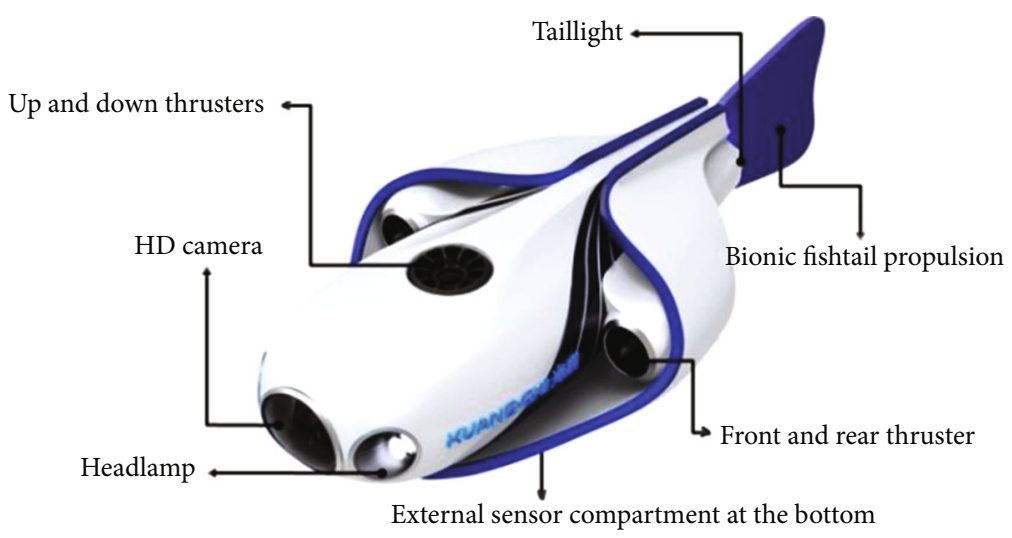

Figure 3: The design layout of the bionic fish.

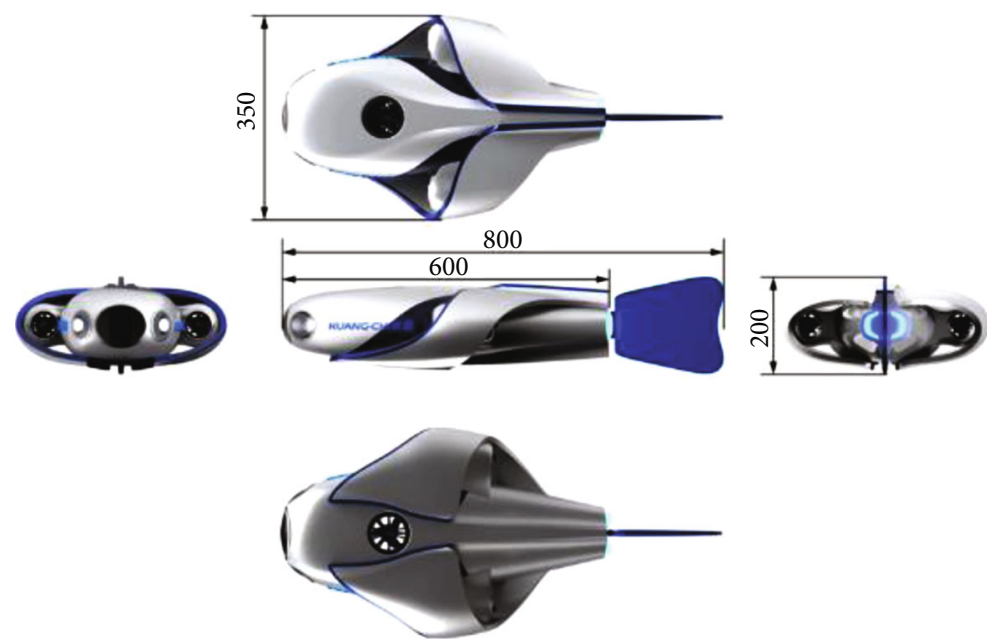

FIgUre 4: The overall size requirements of the bionic fish.

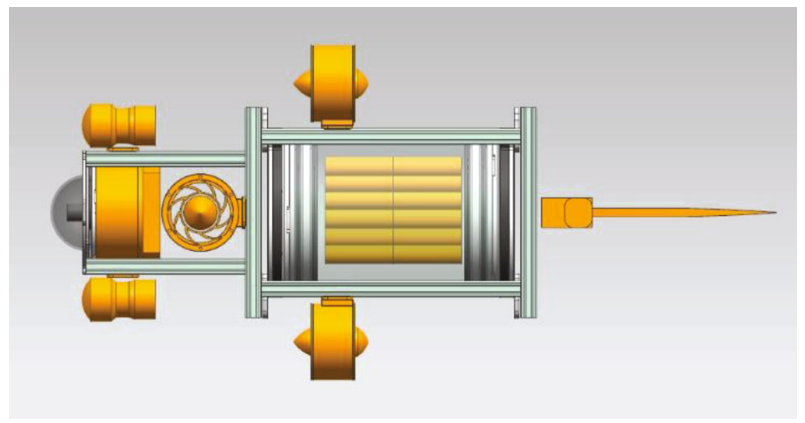

FIGURE 5: Overall structure layout.

craft can move in deeper waters and have a wider range of work. Light weight is undoubtedly one of the most important factors for underwater bionic fish. The lighter structure indicates that the smaller the buoyancy required by the robot, and the corresponding volume of the buoyancy block will be correspondingly reduced. The reduction of the overall volume of the bionic fish is directly reflected in the resistance of the water body to the bionic fish during normal operation, and the bionic fish will be more

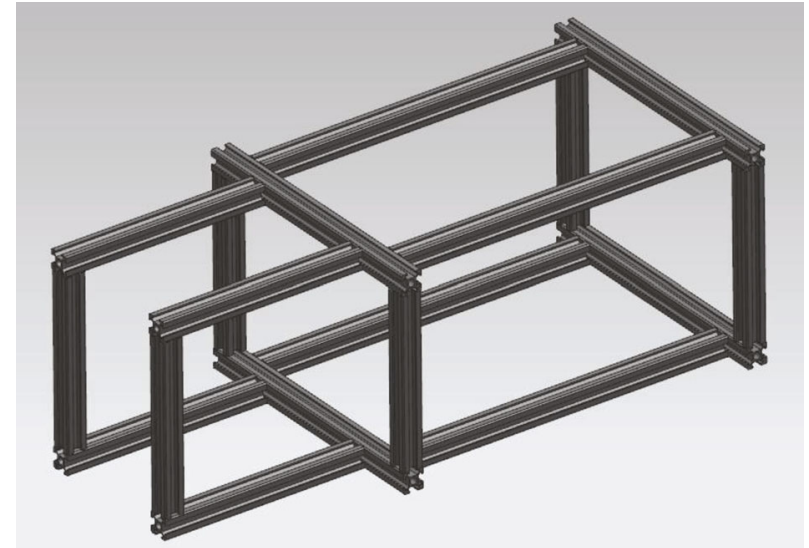

FIGURE 6: Frame structure diagram.

flexible. Therefore, we choose acrylic as the tank material of the underwater robot.

Of course, the function of the cabin barrel is to protect the chip circuit, but it must be wired into the cabin from the outside, such as the power line of the propeller. How to provide more outlets on the premise of maintaining its 
TABLE 1: Chemical composition table of standard aluminum profile 6063.

\begin{tabular}{ccccccccccc}
\hline Grade & $\mathrm{Si}$ & $\mathrm{Fe}$ & $\mathrm{Cu}$ & $\mathrm{Mg}$ & $\mathrm{Cr}$ & $\mathrm{Mn}$ & $\mathrm{Zn}$ & $\mathrm{Ti}$ & Other elements \\
\hline 6063 & $0.2-0.6$ & 0.35 & 0.1 & $0.49-0.9$ & $\leqq 0.1$ & $\leqq 0.1$ & $\leqq 0.1$ & $\leqq 0.1$ & $\begin{array}{c}\text { Single } 0.05 \\
\text { All } 0.15\end{array}$ & Margin \\
\hline
\end{tabular}

TABLE 2: The description of mechanical properties of profile 6063.

\begin{tabular}{lcc}
\hline \multicolumn{2}{c}{ Mechanical properties of APAS industrial aluminum profiles } \\
\hline Material and state & $6063 \mathrm{~T} 5$ & $6063 \mathrm{~T} 6$ \\
Tensile strength & $180 \mathrm{MPa}$ & $270 \mathrm{MPa}$ \\
Yield strength & $127 \mathrm{MPa}$ & $202 \mathrm{MPa}$ \\
Elastic modulus & $68600 \mathrm{~N} / \mathrm{mm} 2$ & $69972 \mathrm{~N} / \mathrm{mm} 2$ \\
Hardness & $62 \mathrm{HB}$ & $72 \mathrm{HB}$ \\
Surface treatment & Anodizing treatment & Plating layer above 12u \\
\hline
\end{tabular}

own sealing has become the key technology of the cabin sealing. We propose a method that uses hollow bolts to accomplish this function.

On the basis of ordinary aluminum alloy bolts, we use the machining center to hollow out the inside, then fix it on the hatch cover, and add rubber O-rings between the bolts and the hatch cover to seal the effect, so that no water can leak into the tank through the thread. The hollowed out part in the middle becomes a whole after the cable passes through and is vulcanized with cold vulcanizing glue, so that only the cable enters the cabin. In order to prevent corrosion of aluminum alloy in seawater, oxidation treatment is also carried out after the late hardening treatment. In order to facilitate the assembly and disassembly of the bolt, the bolt and nut are equipped with a wrench slot, the use of special wrench to match the installation, but also because of the small size of the special wrench, so that the end cover can be installed on the more dense sealing bolt. The principle is shown in Figures 8 and 9.

\subsubsection{Inspection and Check of Tank Drum Sealing Structure.} Due to the particularity and importance of the sealed chamber, we need to test and inspect its sealing condition. In the production process of before, we usually use the real scene of capsule on inspection, is generally after battening cold water soak 3-4 hours, through the tank barrels placed inside the waterproof paper color change to determine whether there is water into, do the limitations are very obvious, and the subtle changes in every time they open tank after sealing. Every time such experiments is not only the result is bad, the risk is very big, cycle is long, with a variety of reasons, we use reverse thinking, and bubble water experiment was formed in order to use the water pressure and hold pressure inside and outside differential pressure seal test, if you will hold internal pressure drop, formed by atmospheric pressure differential pressure to test more convenient and intuitive.

Under this idea, we prepared a set of vacuuming equipment, using the same principle, the hollow bolt as the test port reserved in the cabin, using the vacuuming equipment to lower the cabin pressure to $-0.45 \mathrm{MPa}$, and keep it for a certain time, through the change of the pressure value on the dial to judge the integrity of the seal. Using this complete and convenient detection scheme, every time the hatch is opened, the hidden danger is very low pressure. Low-cost solution for vacuuming is shown in Figures 10 and 11.

3.3. Dynamic Layout of Bionic Fish. The biggest difference between the bionic fish and ordinary underwater robots is the power system. As mentioned above, in order to meet the needs of movement, the hybrid propulsion method is adopted, which is a very new idea in the field of underwater robots. The combination of the powerful power of the propeller and the bionic fish tail gives consideration to the endurance and quick reaction ability. Attitude control is the core of underwater robot control. In order to improve the control accuracy of underwater robot, a posture sensor with good performance is particularly important.

3.3.1. Propeller Layout. In order to control the size of the battery, the number of thrusters needed to be reduced to ensure that the thrusters could provide enough thrust to drive the whole fish, while reducing the power output of the system. So, we have a classic three-propeller layout [11-14].

In the layout, the blue propeller is the positive propeller, and the green propeller is the antipropeller. The hybrid propulsion propeller layout: the three thrusters are divided into vertical thrusters, left thrusters, and right thrusters. The vertical thruster controls the vertical movement of ROV, while the left and right thrusters control the forward and backward movement of ROV and the left and right turning movement [14]. The spin generated during normal operation of the No. 3 vertically mounted thruster is offset by the difference between No. 1 and No. 2 thrusters to form a stable motion.

3.3.2. Propeller Selection. According to the actual use requirements, we choose a propeller provided by Lezhi Robot Company according to the advice of our instructor. As the power source of the propeller cabin in the overall structure of Lezhi Robot, this type of propeller has the advantages of low power consumption and small volume. Specifications and parameters are shown in Table 3, motor wiring diagram is shown in Table 4, and actual working measurement parameters are shown in Table 5 [15].

3.3.3. Layout and Selection of Bionic Fish Tail. In order to meet the requirements of long endurance, we propose a separate propulsion mode of the bionic fish tail. In order to make the fish tail drive the whole bionic fish structure, the installation position of the fish tail must be at the end of the whole mechanism. The power mainly comes from the waterproof steering gear, which is fixed on the robot frame, and the rotating shaft is connected with the tail fin, through 


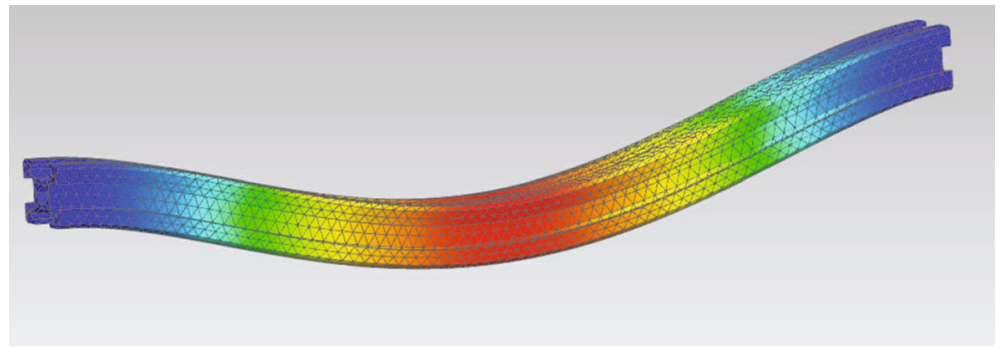

Figure 7: Force analysis diagram of 6063.

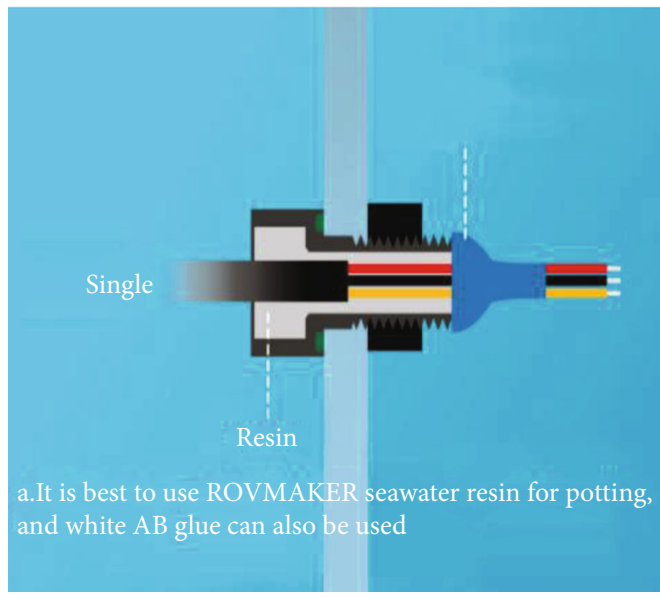

FIgURE 8: Working principle diagram of sealing bolt.

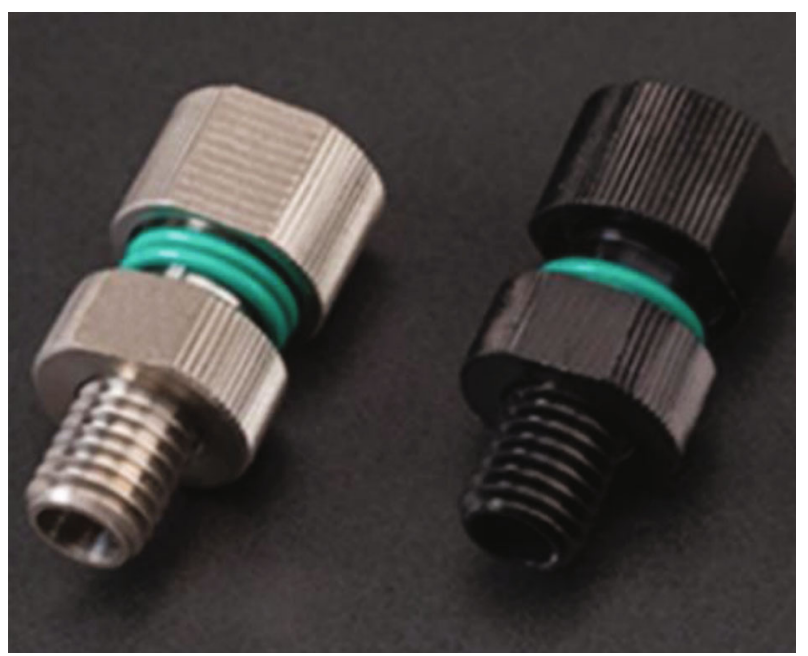

Figure 9: Physical map of sealing bolt.

the steering gear back and forth regular movement to promote the robot forward, left, and right turn $[16,17]$.

The requirements for waterproof steering gear mainly depend on its waterproof sealing performance and power output capacity, and of course, its power should also be considered. To sum up, we choose a waterproof steering gear provided by ROVMAKER with a pressure rating of 300 meters and power output capacity of $34 \mathrm{~kg} . \mathrm{cm}$.

As a moving part, the tail fin is made of silica gel with zero harm to the human body. The size and shape, including

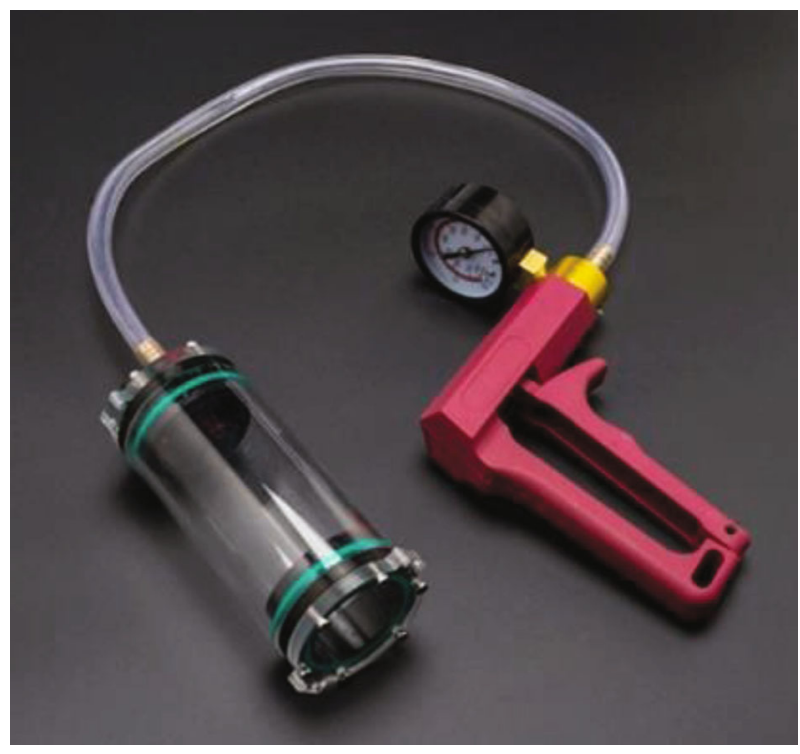

FIGURE 10: Working principle diagram of sealing bolt.

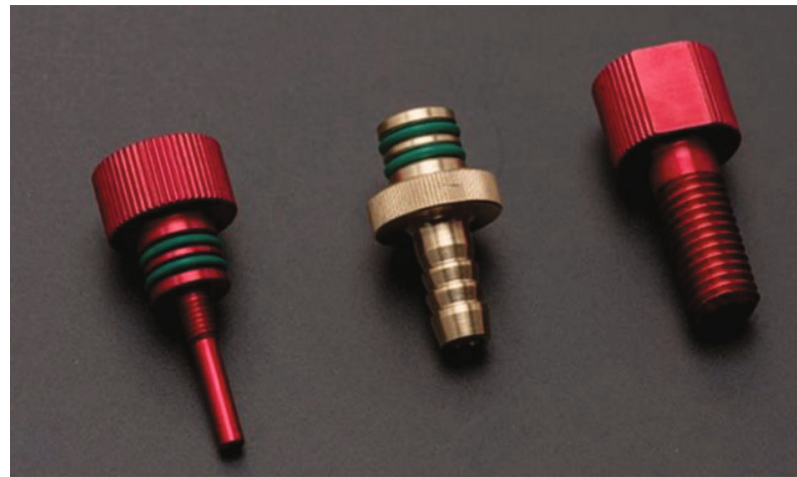

Figure 11: Physical map of sealing bolt.

the change of hardness gradient and other properties, need to be bionic and a lot of tests to summarize the optimal shape and hardness ratio. Here, we refer to the boya Gongdao BIKI bionic fish tail fin, equal scale amplification, that has achieved the initial requirements. Step change of fin thickness in top view is shown in Figure 12.

\subsection{Design and Check Tank Barrel and Propeller Fastener}

3.4.1. Design of Tank Barrel Fastener. After the tank is designed and made, it must be positioned and installed 
TABLE 3: Propeller specification parameter.

\begin{tabular}{lc}
\hline Brand & Lezhi \\
\hline $\begin{array}{l}\text { Product } \\
\text { number }\end{array}$ & Single joint head compartment \\
Size & $98 \mathrm{~mm}$ (the maximum diameter) \\
Weight & $108 \mathrm{~mm}$ (length) \\
$\begin{array}{l}\text { Operating } \\
\text { voltage }\end{array}$ & $262.4 \mathrm{~g}$ \\
$\begin{array}{l}\text { Control } \\
\text { method }\end{array}$ & $5 \mathrm{~V}-16 \mathrm{~V}$ \\
\hline
\end{tabular}

TABle 4: Propeller specifications.

\begin{tabular}{lcc}
\hline Black line & GND & Power negative \\
\hline Red line & DC $5 \mathrm{~V}-16 \mathrm{~V}$ & Power positive \\
White line & CANL & CAN bus L \\
Yellow line & CANH & CAN bus $\mathrm{H}$ \\
\hline
\end{tabular}

according to the installation holes reserved for it. Because there are gyroscopes and other sensors in the cabin, it is particularly important to install them in accordance with the requirements. We used the mounting hole reserved on the hatch cover at the beginning to design the outer fixing ring. In order to ensure both strength and lightweight, aluminum alloy is preferred as the material of the fixing ring. In terms of processing, we process a $20 \mathrm{~mm}$ thick aluminum block to the specified size and then process the plate gold through the bending machine until it reaches the specified size.

3.4.2. Propeller Fastener Design. The purpose of the propeller fastener is mainly to fix the propeller to the frame. Due to the aluminum alloy profile frame, we can directly use the preset slot on the profile to fix the propeller. We only need to measure the distance between the two slots to design the fixing hole on the fixing plate. The requirements of the connecting piece are to fix the propeller and the profile of the outer frame; so, there is no very high assembly and installation accuracy. In view of the above, in terms of processing, we choose to use relatively cheap aluminum plate for processing. In the processing mode, we choose to use laser cutting machine for laser processing, and the precision error of laser processing is about $0.3-0.5 \mathrm{~mm}$, which meets the precision requirements of the connector.

3.5. The Making of Bionic Fish Shell. The bionic fish shell is mainly divided into shell and buoyancy in terms of function and structure, which are, respectively, introduced below.

3.5.1. The Making of Outside-Bionic Fish Shell. On the basis of the completion of the existing mechanical mechanism design, we started the design of the bionic fish shell and began to make it after the design was completed. We have generally developed the following schemes: (1) open injection molding, (2) FRP customization, (3) carbon fiber inverted mold, and (4) 3D printing: considering the production cost and production cycle, we finally choose to use the most commonly used $3 \mathrm{D}$ printing technology to make the shell.

$3 \mathrm{D}$ printing is a kind of rapid prototyping technology, based on digital model files, using adhesive materials to build objects layer by layer. At present, PLA (polylactic acid) is commonly used as the adhesive material, which has the advantages of low material cost, degradability, fast printing speed, and so on. The processing temperature is $170 \sim 230^{\circ} \mathrm{C}$. First of all, we completed the modeling, then exported the model into STL format, and processed the files with the slicing software Simplify $3 \mathrm{D}$. According to the different parts, the process was roughly divided into the following steps: (1) and (2) adjust parts orientation, (3) add auxiliary support, (4) select printer parameters, (5) slice and preview, and (6) export data from SD card and print slices.

In for the correct operation after we started using 3D printer to print production, after the import file need to be prepared to some of the early work, because the volume of the shell is larger, the slicing software interface can also show the materials needed to print out; so, the first step is to check if the material on the shelf material enough. The second part is the beginning of preheat printer hot bed, because the print heads out of print materials heat up to $195^{\circ} \mathrm{C}$, if the cooling too quickly could lead to rapid changes in material internal stress, but if print plane has certain temperature, and can delay the printing material of cooling speed, the most intuitive effect is to print out parts will not become warped edge.

Third step can then began to run the program and the nozzle to the prescribed temperature after heating printers start executing the program, and the printing material on the plane at this time we need to see whether the binder is too tight or too loose will influence the quality of the print; at this point, we need to print plane for leveling work, to ensure that the print process smoothly. The printing process is shown in Figure 13.

\section{Design and Implementation of Bionic Fish Fin}

The fin is not just a decoration in the whole bionic fish system, but rather, it is the core of the communication system. In order to give the whole fish a wider range, we eliminated the very stable umbilical cord that we had been using to connect the ground station to the ROV, and as a way of transmitting signals, the cable was the most stable and convenient option. It is well known that water can absorb and shield communication signals. How to achieve real-time control between the robot and the ground station after canceling the direct connection between the robot and the ground station has become our primary concern.

In terms of the choice of communication mode, we chose Wi-Fi communication mode according to its range of motion and cost and took it as the starting point for functional design of communication part. Wi-Fi is also known as "mobile hotspot." We install a Wi-Fi module on the robot to control signal and video stream receiving and receiving. However, in practical application scenarios, the bionic fish often needs to sink to more than 3 meters 
TABLE 5: Propeller working parameters.

\begin{tabular}{lcccc}
\hline Name & Brand & Weight $(\mathrm{g})$ & Size $(\mathrm{mm})$ & Control method \\
\hline BD-36 underwater propeller & Lezhi & In the air: 212 & $\begin{array}{c}\text { Length:94.5 } \\
\text { Diameter:64 }\end{array}$ & PWM output control \\
\hline
\end{tabular}

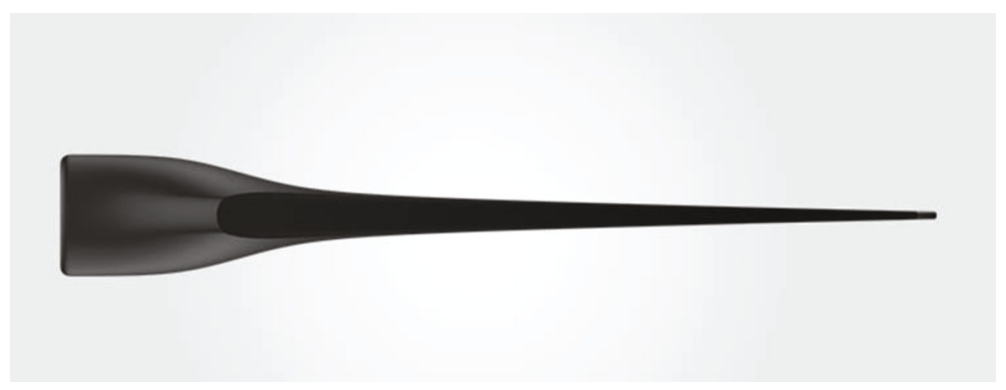

Figure 12: Schematic diagram of the top section of the fin.

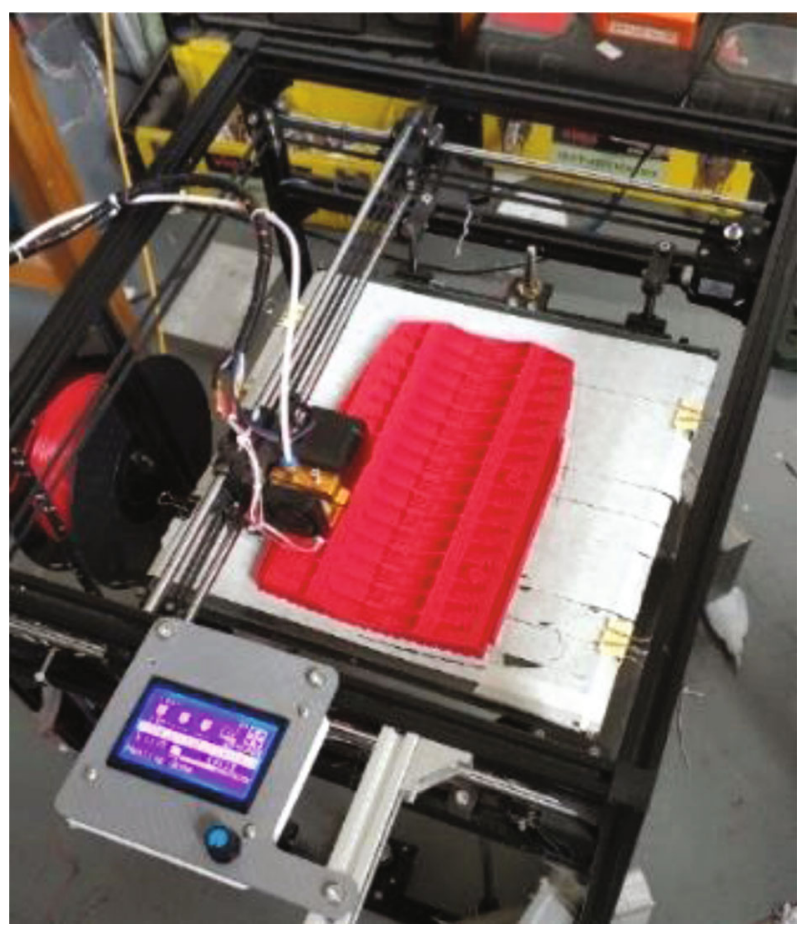

FIGURE 13: Slicing software.

of water, and the electromagnetic wave is absorbed layer by layer by the water body. The bionic fish cannot receive any electromagnetic signal underwater, and the $\mathrm{Wi}-\mathrm{Fi}$ module is only in name.

Based on the above issues, we intend to use an innovative design in full discussion. Based on the online materials as reference, we imitate the structure of a mother-child ship. By using a floating structure shaped like a fish fin, an enclosed space is created inside to house the chip circuit board, with the Wi-Fi antenna at the top of the float. The floating robot is connected with the floating robot through zero buoyancy cable. The underwater video stream shot by the bionic fish is transmitted through the power carrier preset in the internal body of the bionic fish and the power carrier on the floating fish. The power carrier in the floating fish will receive the data. Below are the design details and implementation scheme of the fin (see Figure 14).

\subsection{Mechanical Structure Design and Manufacture of Bionic} Fish Fin. According to the previous function description, first, we need to design its shape into the shape of fish fin. In addition, enough space should be reserved inside to accommodate the power carrier and router, and a small hole should be reserved at the top of the fin to extend the antenna of the Wi-Fi module out of the cabin to help the antenna receive and send signals well.

Capsule in the design when we refer to the design of the circular tank barrels uses the combination of the flange end cover for waterproof seal, because it only needs to have a power carrier cable into the module, so much on the hatch cover does not need to open holes, simply leaves a power carrier cable threading screw holes, and does test holes for the air test. In order to ensure that it has a certain waterproof and sealing performance, we adopt a structure similar to lezhi water robot waterproof tank barrel for structural design. The structure of the tank barrel is shown in Figure 15 [18, 19].

Robot KenFish lexrev company team will be the water according to the different parts of functional division, KenFish single joint suite is a multipurpose water robot contest teaching platform, and the platform is given priority to with sensing, control, and able to meet the needs of all kinds of colleges and universities students to learn and practice, but also suitable for students in extracurricular development challenge, innovation, competition, and subject. KenFish single joint kit meets the requirements of the International Underwater Robot Competition project team and obtains the product authorization letter from the International Underwater Robot Alliance. The mechanical movement part of KenFish single-joint kit uses bionics technology to simulate the swimming mode of fish, so that the robot can move continuously and freely in water, with propeller propulsion mechanism, sensing mechanism, rotating mechanism, and other mechanical structure, so that the robot can carry out 


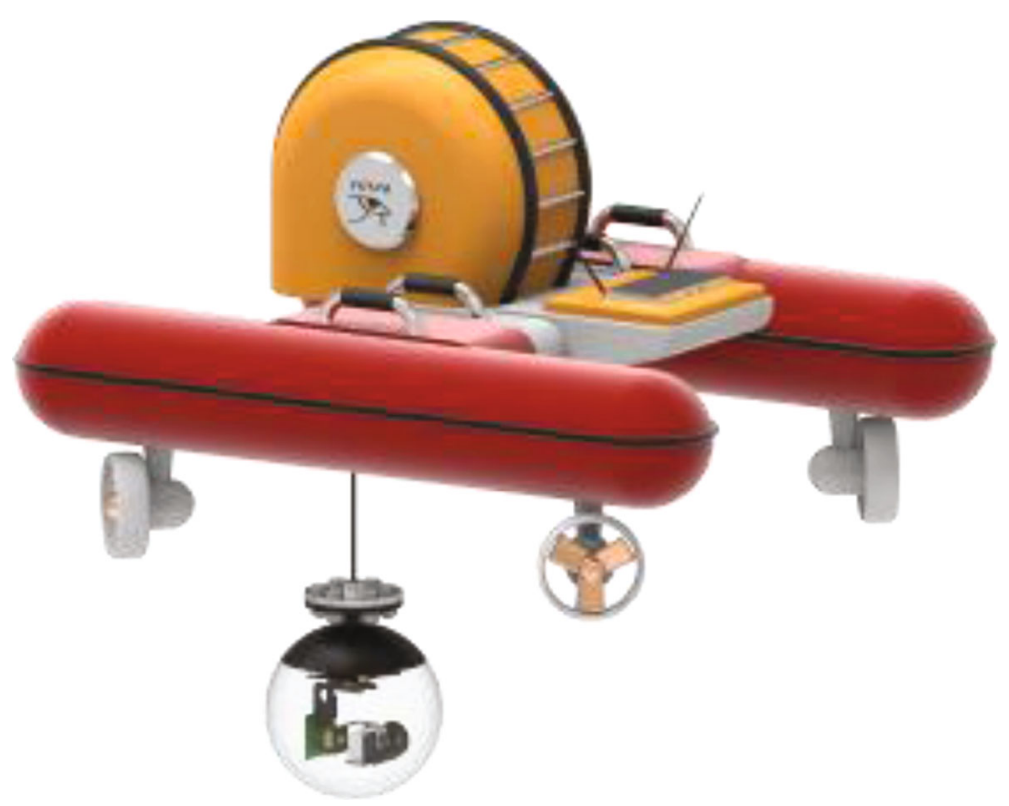

Figure 14: Schematic diagram of the child and mother ship structure.

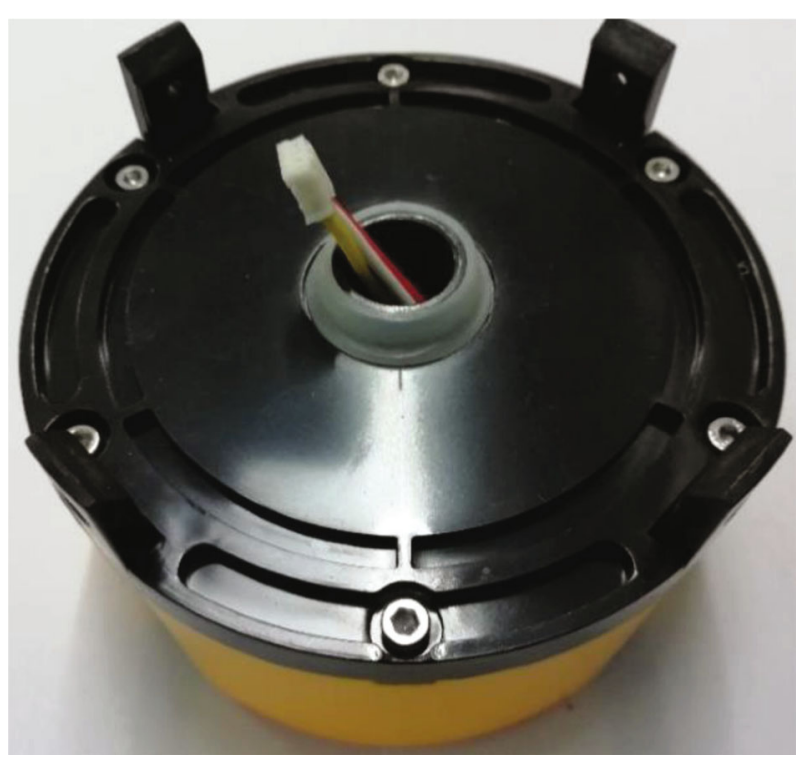

FIgURE 15: Structure diagram of the sealing method of Lezhi underwater robot.

more ways of movement. Equipped with a vision cabin, it can transmit 720P HD video in real time and store images. Suite is divided into single joint head tank processor module, a standard module of balancing module, oscillating propulsion control module, sensor module, the propeller propulsion module, module through standard PH2.0 $4 \mathrm{p}$ port connection between modules, include the power cord and CAN bus communication, convenient communication between each module, can be flexible enough to increase or decrease in hull, and convenient user study and extracurricular expanding. It provides an efficient and reliable platform for users to carry out underwater applications. The rapid increase and decrease of the cabin are the char- acteristics of this robot; so, a reliable and convenient waterproof method has become the core of this function. Through the deep understanding of this sealing principle, we refer to this structure for floating waterproof sealing structure design.

The principle of this sealing method is to add a layer of soft silica gel ring between the two connectors, through the compression force to make the soft silica gel deformation, so as to fill the gap between the two connectors, and this process in how to produce effective positive pressure between the two parts becomes the main point of consideration. We need to add a sealing structure at the bottom of the float, so as not to damage the overall structure of the upper end of the float and not to damage its external streamline overall more beautiful.

According to the above argument, the floating structure is divided into two parts: (1) upper fin shape and bracket structure and (2) lower sealing cover structure. The two structures are connected by screws, and the positive pressure generated after screw tightening is used to deform the soft silica gel ring, thus creating a closed space. The fin shape assembly effect is shown in Figure 16.

4.1.1. The Design of Upper Fin Shape and Bracket Structure and Lower Seal Cover Structure. The shape of the upper fin and the structure of the bracket are characterized by streamlined shape design to reduce the influence of fluid resistance on the normal movement of the float. The internal frame structure is supported to improve the strength of the outer shell, so that the shell has a certain compressive capacity, but also can provide the corresponding installation position for the hardware chip. At the bottom of the whole structure, we reserved a ring of M3 screw bottom holes around the edge of the shell. In order to facilitate the positioning and installation of the lower sealing cover structure, the design of step provides a positioning foundation, and the step can 


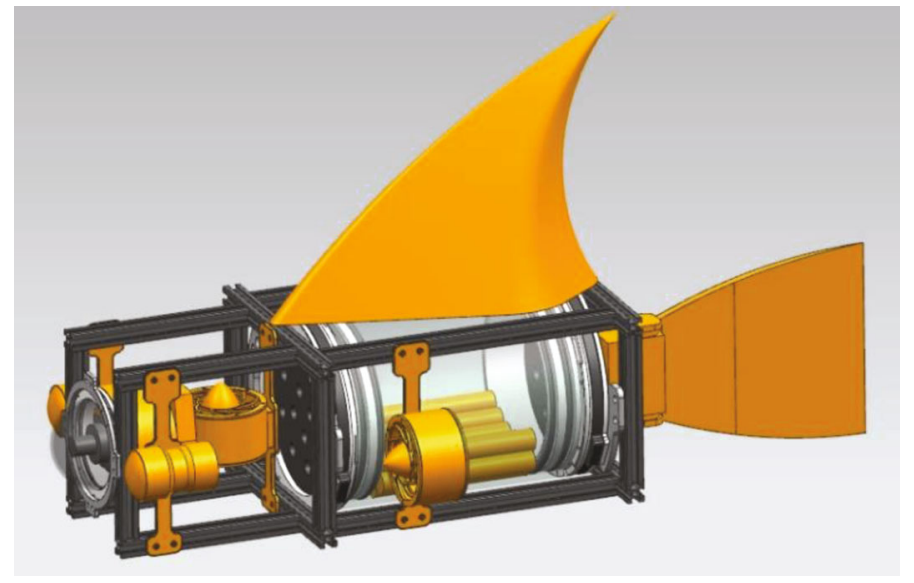

Figure 16: Effect picture of fin assembly.

also produce a certain auxiliary sealing function after the coordination of the two parts of the structure.

The function of the lower seal cover structure is mainly two, one is to connect with the upper fin shape and bracket structure to form a sealed cavity, in order to accommodate the hardware chip circuit board. The second is to provide a certain number of threading screw holes, so that the umbilical cable out of the main body of the underwater bionic fish can be connected to the float and to provide a sealing test port to test the sealing performance. Cushion a layer of soft silica gel ring in the middle of the two structures, the two structures are connected and pressed by screws, and the compression force makes the soft silica gel ring deformation to fill the gap of the contact surface to meet the requirements of sealing.

\subsubsection{Application Example and Effect of Net Bridge in Fish} Fin. The video data generated by the underwater bionic fish in the underwater shooting needs to be transmitted through a device after the transmission of the power carrier module and the power carrier module on the fin. At this time, we need a communication transmission module to achieve this function. After comprehensive consideration in terms of production cost and other aspects, Wi-Fi communication is undoubtedly the most convenient, efficient, and simplest solution. However, its disadvantage is also fatal; that is, its effective transmission distance is very limited, which has a great impact on the normal movement of the bionic fish. On this basis, we searched materials. It is decided to use the bridge as the communication module between the bionic floating fish and the ground station.

A Bridge, also called a Bridge, is a storage/forwarding device that connects two LANs. It can divide a large LAN into multiple network segments or interconnect more than two LANs into a logical LAN so that all users on the LAN can access the server. Expansion of the most common method is to use the bridge; according to the survey, on the market, the vast ShuWang bridge of the communication ability is very strong, we have chosen a very high cost performance digital bridge, when used correctly, and its effective communication distance is $9 \mathrm{~km}, 900 \mathrm{~m}$ more than communication ability in the process of actual use. Of course, it should be noted that the network bridge needs to be used in pairs, and its use angle is horizontal $\pm 30^{\circ}$, in the installation of the need to pay attention to the direction, in order to ensure the best use effect [20].

In terms of power, the bridge of the power supply must be up to standard and smooth, not smooth needs to choose higher power supply voltage, but now, the fins is used in electric power carrier module, and it is a power interface and can be used directly the output power to supply the normal work of the bridge; of course, we need a voltage regulator module to module of the output voltage of electric carrier for processing, in order to prevent the substandard power supply leading to the bridge equipment frequent offline.

In the process of actual use, we placed on the fins on each side of a bridge and to form a comprehensive range of delivery status, so whatever floats in which bearing always has the direction of the signal back to ground station layout bridge, back to the video is clear, keep within 0.51 seconds delay, picture frame loss ratio is very small, and this scheme is proved practical.

\section{Conclusion}

After indepth discussion and research, combined with the actual production, we explore a new type of abled underwater robot communication scheme, through the electronic carrier module to transmit the video signal to the floating, and then by the floating internal bridge transmission, realize the real-time transmission of video signal and real-time control signal receiving and execution. With the addition of the fin floating structure, the whole bionic underwater robot gets rid of the shackle between the traditional umbilical cable and the ground station, making the movement of the bionic fish more free under water. In addition, ROV's real boat test is difficult and costs a lot of money and time. Many control studies, especially in China, only stay in the simulation stage. The application of fuzzy control [21,22], neural network control and sliding mode control or their combination in ROV control is worth discussing and further deepening. After the completion of the whole system, according to the actual operation results, the hybrid propulsion underwater 
bionic fish has practical application value and has broad development prospects in the consumer market.

\section{Data Availability}

The dataset used to support the findings of this study are available from the corresponding author upon request.

\section{Conflicts of Interest}

The authors declare no conflicts of interest.

\section{Acknowledgments}

This work was supported by the "Structure Design of Wheeled Propeller of New Type Underwater Robot and Optimal Design of Open Water Performance" (Project No. CXY202014).

\section{References}

[1] Q. Li, J. Zhang, J. Hong, D. Hu, Y. Yang, and S. Guo, “A novel undulatory propulsion strategy for underwater robots," Journal of biomimetic Engineering, vol. 18, no. 4, pp. 812-823, 2021.

[2] L. Shi, Y. Hu, S. Su et al., "A fuzzy PID algorithm for a novel miniature spherical robots with three-dimensional underwater motion control," Journal of Bionic Engineering, vol. 17, no. 5, pp. 959-969, 2020.

[3] F. Shahbazi, M. Mahmoodi, and R. Ghasemi, "Fractionalorder super-twisting sliding-mode procedure design for a class of fractional-order nonlinear dynamic underwater robots," Engineering, vol. 19, no. 1, pp. 64-71, 2020.

[4] H. Zhou, T. Hu, H. Xie, D. Zhang, and L. Shen, "Computational and experimental study on dynamic behavior of underwater robots propelled by bionic undulating fins," Science in China: Technical Sciences, vol. 53, no. 11, pp. 2966-2971, 2010.

[5] J. Poncela and M. C. Aguayo-Torres, "A framework for testing of wireless underwater robots," Wireless personal communications, vol. 70, no. 3, pp. 1171-1181, 2013.

[6] K. Ku, R. S. Bradbeer, K. Lam, L. F. Yeung, and R. Li, “A novel actuator for underwater robots," IEEE Journal of Oceanic Engineering, vol. 34, no. 3, pp. 331-342, 2009.

[7] X. S. Meng, H. G. Xu, and M. J. Zhang, "Research on framework for formation control of multiple underwater robots in a dynamic environment," Journal of Harbin Engineering University, vol. 3, no. 2, pp. 36-41, 2004.

[8] V. F. Filaretov, A. V. Zuev, A. N. Zhirabok, A. A. Procenko, and B. Subudhi, "Development of synthesis method of fault tolerant systems for autonomous underwater robots with navigation sensors failures," in 2015 23rd Mediterranean Conference on Control and Automation (MED), pp. 335-340, Torremolinos, Spain, 2015.

[9] K. Underwood, "Perceptive Underwater Robots," Signals, vol. 73, no. 4, pp. 26-28, 2018.

[10] M. P. Vicmudo, E. P. Dadios, and R. R. P. Vicerra, "Path planning of underwater swarm robots using genetic algorithm," in 2014 International Conference on Humanoid, Nanotechnology, Information Technology, Communication and Control, Environment and Management (HNICEM), pp. 1-5, Palawan, Philippines, 2014.
[11] D. Hubbard, "Hybrid propulsion pushes ahead - refinements lead to next generation technology," Bus Ride, vol. 43, no. 3, pp. 32-34, 2007.

[12] L.-Y. Wang and P.-J. Wang, "Maglev systems based on combined propulsion and levitation hybrid technology," Journal of Robotics and Mechatronics, vol. 13, no. 1, pp. 6-11, 2001.

[13] S. A. Whitmore, "Additive manufacturing as an enabling technology for "green" hybrid spacecraft propulsion," in 2015 7th International Conference on Recent Advances in Space Technologies (RAST), pp. 1-6, Istanbul, Turkey, 2015.

[14] H. Masto and G. DeRossi, "UK's Royal Fleet of tankers to use GE drive technology for energy-efficient hybrid propulsion," Ocean News \& Technology, vol. 18, no. 11, pp. 19-20, 2012.

[15] D. Qi, C. Zhang, J. He, Y. Yue, J. Wang, and D. Xiao, “Observation and analysis of diving beetle movements while swimming," Scientific Reports, vol. 11, no. 1, 2021.

[16] K. Jost, "Space technology: hybrid propulsion enables low-cost space travel," Aerospace Engineering, vol. 24, no. 10, pp. 28-29, 2004.

[17] Y. Li, L. Chen, Y. Wang, and C. Ren, "Design and experimental evaluation of the novel undulatory propulsors for biomimetic underwater robots," Bioinspiration \& Biomimetics, vol. 16, no. $5,2021$.

[18] V. F. Filaretov, D. A. Yukhimets, A. V. Zuev, A. S. Gubankov, and D. D. Minaev, "Development of a digital platform for the implementation of distributed control and navigation systems for underwater robotic systems performing technological operations in Arctic," IOP Conference Series: Earth and Environmental Science, vol. 816, no. 1, 2021.

[19] M. J. Islam, J. Mo, and J. Sattar, "Robot-to-robot relative pose estimation using humans as markers," Autonomous Robots, vol. 45, no. 4, pp. 579-593, 2021.

[20] G. Govindarajan and R. Sharma, "Experimental investigation on a flapping beam with smart material actuation for underwater application," Mechanics of Advanced Materials and Structures, vol. 28, no. 10, pp. 1020-1034, 2021.

[21] Y. Jiang, X. Gu, D. Wu et al., "A novel negative-transferresistant fuzzy clustering model with a shared cross-domain transfer latent space and its application to brain CT image segmentation," IEEE/ACM Transactions on Computational Biology and Bioinformatics, vol. 18, no. 1, pp. 40-52, 2020.

[22] Y. Jiang, Y. Zhang, C. Lin, D. Wu, and C.-T. Lin, "EEG-Based driver drowsiness estimation using an online multi-view and transfer TSK fuzzy system," IEEE Transactions on Intelligent Transportation Systems, vol. 22, no. 3, pp. 1752-1764, 2021. 